owing to deficiency of antibodies. The only female patient described so far $^{s}$ presented with a severe normochromic anaemia with hepatosplenomegaly, and the lymph-node enlargement could be detected only in mediastinal glands on $x$-ray examination. Two of the patients had occult prostatic cancers in addition to the malignant lymphomas.

Histologically, heavy chain disease is characterized by proliferation of reticulum cells mixed with abnormal lymphoid and immature plasma cells. In two cases the diagnosis of Hodgkin's disease was entertained at first owing to the presence of binucleate cells resembling the Reed-Sternberg cell.

The nature of the abnormal protein has been thoroughly studied. The IgG molecule consists of two "heavy" polypeptide chains and two "light" chains; they are linked together by disulphide bonds. The heavy chains can be split in half at a certain point by papain. This separates the Fc (=crystallizable) fragment, which consists of the rear portion of the heavy chain pair from the front half of the heavy chains, called Fd fragments, which remain attached to the light chains to form the $\mathrm{Fab}$ (= antigen-binding) portion of the molecule.

The paraprotein made in heavy chain disease is almost identical with the papain-split Fc fragment of normal IgG. There may be slight variations in the length of the chains in different patients, but the most interesting results have come from a study of the amino-acid sequences" of the " $\mathrm{N}$-terminal" end of the chains, where synthesis of the molecule begins, and of the "C-terminal" end, which represents the last portion synthesized. Experiments have shown that the heavy chain is made in one sequence instead of the $\mathrm{Fd}$ and the Fc halves being made separately and then joined up. Therefore it is of great interest that in heavy chain disease the $\mathrm{N}$-terminal and $\mathrm{C}$-terminal are both normal, while the light chains and the intervening part of the $\mathrm{Fd}$ fragments are missing. This suggests that in the clone of malignant cells a deletion has occurred in the genetic mechanism which directs the production of this part of the heavy chain.

The serum proteins found in patients with myeloma have been invaluable for charting the various classes and subclasses of immunoglobulin. The Fc fragments carry the antigenic determinants for the four known subclasses of IgG. ${ }^{6}$ And, since the distribution of different myeloma globulins in the population follows the pattern found in normal individuals, it is likely that observations on further cases of heavy chain disease will disclose the existence of $\mathrm{Fc}$ fragments corresponding to other immunoglobulin classes.

\section{Control of Measles}

Sunday, 23 January 1966 was called " End Measles Sunday " in Rhode Island, U.S.A., because a large-scale operation in preventive medicine was undertaken then. Its purpose was to raise the proportion of the juvenile population that was resistant to measles to such a level that epidemics of the disease would no longer be possible-in other words to bestow on it " herd immunity." A recent report ${ }^{1}$ indicates that this goal has been successfully achieved. For this reason, and because Rhode Island is one of the only two States in the U.S.A. which is comparable in both area and population to a British county, the experiment is of interest here in Britain, where large-scale vaccination against measles is now being undertaken.

The strategy, tactics, and execution of the initial immunization campaign ${ }^{3}$ are reminiscent of those of the diabetes detection drive undertaken in Bedford in April 1962.45 Both entailed closely co-ordinated planning between local health authorities, the doctors responsible for the clinical care of the population, and the staff of a medical school (in one case Guy's Hospital and in the other Yale University). Both were preceded by a carefully planned publicity campaign; both involved the massive and enthusiastic assistance of voluntary workers; both reached between 65 and $70 \%$ of the target population; and both were followed by intensive surveillance.

In Rhode Island a vaccine made from a live attenuated virus (Schwarz) ${ }^{6}$ was administered with multiple-dose jet injector guns. Surveillance was the responsibility of an epidemic intelligence officer posted to Rhode Island from the National Communicable Disease Centre, Atlanta, Georgia. Every new case of measles was reported to the State Department of Health, and when possible the cases were examined clinically by members of the staff of that department. In all, the study lasted 15 months, for the first six months of which the serum of all suspects was subjected to serological investigation.

Of 71 suspected cases, $42(59 \%)$ were found to be clinically compatible with measles. Blood was obtained from 32 of these but in only $10(31 \%)$ could serological confirmation of the diagnosis be found. A further 17 had antibody patterns suggestive of measles infection in the past.

Of the 42 " clinically compatible" cases 14 were solitary, indicating a high prevalence of immunity among their contacts, and the remaining 28 occurred in five clusters, four of which comprised fewer than six persons and the fifth comprised 14. The most frequent source of the disease was an out-of-State visitor ; the families of men in the Forces were often affected. The incidence of the disease per 100,000 during the 15-month period was 5.0 among the highest of three social classes, 6.4 in the middle, and 3.0 among the lowest. It is assumed that this distribution is because the poorest people were the least likely to have out-of-State visitors.

From the clinical point of view many of the cases were bizarre. Fourteen of the 42 developed in people who had had previous disease, and in one of these there was serological evidence in support of the view that a second attack did indeed occur. In contrast several patients had an illness in every way typical of measles-including Koplik's spots in three of them-without any serological evidence of having recently been infected by the measles virus.

The Rhode Island experiment has some valuable lessons for us. To begin with it shows clearly that a well-planned and executed single-day campaign can transform a susceptible population to one which has "herd immunity." Secondly it shows that artificially endowed herd immunity to measles is every bit as effective as the theorists would lead us to expect and that the side reactions are not sufficiently serious or frequent to interfere significantly with school attendance. ${ }^{2}$ In

\footnotetext{
1 Schaffner, W., Schluederberg, A. E. S., and Byrne, E. B., New Engl. F. Med., 1968, 279, 783 .

2 Byrne, E. B., Rosenstein, B. J., Jaworski, A. A., and Jaworski, R. A., 7. Amer. med. Ass., 1967, 199, 619.

3 Bowes, J. E., Publ. Hlth Rep., 1967, 82, 409.

- Sharp, C. L., Proc. roy. Soc. Med., 1964, 57, 193.

Butterfield, W. J. H., Proc. roy. Soc. Med., 1964, 57, 196.

- Schwarz, A. J. F., Ann. Paediat., 1964, 202, 241.
} 
no case in which serological studies were made was there evidence of vaccine failure. It also shows that the word "eradicate"-which literally means tear up by the roots and so destroy for ever-is inappropriate for this control procedure. This word is used by the Rhode Island/Yale group, as it is by many other American workers, despite the fact that one of the most important findings is that measles continues to exist, though in modified form, and will so continue so long as people from susceptible populations visit their friends and relations. Therefore no country can expect to eradicate the disease until the entire population of the world is immune or it effectively isolates itself from all social intercourse with all other countries. Finally the Rhode Island experiment emphasizes that not all that is morbilliform is really measles.

\section{Age and Joint Mobility}

That 74-year-old joints resent a game of Rugby football is well known, but little has been done to measure this stiffness quantitatively or qualitatively. The extensibility of the little finger has been assessed by placing the extended hand on a flat surface and extending the little finger as far as comfortably possible, the angle being measured in multiples of $15^{\circ}$ with a protractor. ${ }^{1}$ J. T. Scott ${ }^{2}$ measured the distance the index finger moved from the horizontal with the application of a spring to its end. He found differences throughout the day with this technique, though the results were not always reproducible, probably owing to changes in the joints from being repeatedly extended.

V. Wright and R. J. Johns ${ }^{4}$ developed apparatus to measure the stiffness of the metacarpo-phalangeal joints quantitatively and qualitatively. They showed a striking increase in stiffness with advancing age. Joint size may contribute to the changes observed up to maturity, but cannot

\footnotetext{
1 Ellis, F. E., and Bundick, W. R., A.M.A. Arch. Derm., 1956, 74, 22.

Scott, J. T., Ann. rheum. Dis., 1960, 19, 361.

s Wright, V., and Johns, R. J., Arthr. and Rheum., 1960, 3, 328.

-Wright, V., and Johns, R. J., Ann. rheum. Dis., 1961, 20, 36.

- Wright, V., and Plunkett, T. G., Ann. phys. Med., 1966, 8, 280.

- Barnett, C. H., and Cobbold, A. F., Ann. rheum. Dis., 1968, 27, 175.

7 Goddard, R., Dowson, D., Longfield, M. D., and Wright, V., foint Meeting of Swiss Society of Rheumatology and Physical Medicine and Heberden Society, Burgenstock, June 1968.

- Dunham, W. F., Physiotherapy, 1949, 35, 69.

- Loebl, W. Y., Ann. phys. Med., 1967, 9, 103.

10 Schober, P., Münch. Med. Wschr., 1937, 84, 336.

11 Macrae, I. F., and Wright, V., Annual Report of Arthritis and Rheumatism Council, 1967, p. 80. London.

12 Gross, J., Amer. F. Path., 1950, 26, 708.

13 Verzar, F., Connective Tissue, a Symposium organised by the C.I.O.M.S., ed. R. E. Tunbridge, 1957, p. 208. Oxford.

14 Keech, M. K., Ann. rheum. Dis., 1955, 14, 19.

15 Tunbridge, R. E., Ann. rheum. Dis., 1957, 16, 6.

16 Kenedi, R. M., Gibson, T., and Daly, C. H., Skin Research-Report No. 2. 1963. Department of Bio-engineering, University of Strathclyde.

17 Ridge, M. D., and Wright, V., Gerontologia (Basel), 1966, 12, 174.

18 Wright, V., Lab. Pract., 1966, 15, 66. 19 Jebens, E. H., and Monk-Jones, M. E., Bone ft Surg., 1959, 41B,

20 Barnett, C. H., and Stockwell, R. A., in Modern Trends in Rheuma tology, ed. A. G. S. Hill, 1966, p. 253 . London.

"Kellgren, J. H., Jeffrey, M. R., and Ball, J., The Epidemiology of Chronic Rheumatism. Symposium organized by C.I.O.M.S., ed. J. H. Kellgren, M. R. Jeffrey, and J. Ball, vol. 1, 1963, p. 326.
Oxford.

22 Bennett, P. H., and Burch, T. A., Bull. rheum. Dis., 1967, 17, 453.
}

explain increases in stiffness after that. The stiffness experienced may in fact be related to both decrease of muscle power and increase of physical resistance at the joint. ${ }^{5}$ C. $\mathrm{H}$. Barnett and A. F. Cobbold ${ }^{6}$ have recently studied this problem in the distal joint of the finger of 111 persons by other techniques. They calculated a "coefficient of friction" (not used in the way an engineer would define it) from the rate of decay of amplitude of a pendulum swinging on the middle finger. They found that the mean coefficient of friction in the finger increased with age, but there was a wide scatter of results, for a few old people had fingers almost as mobile as other people had in youth.

Techniques of measurement have recently been devised for larger weight-bearing joints and a similar increased stiffness with age detected. ${ }^{7}$ Attempts at measuring joint mobility in the spine have been confined to forward flexion ${ }^{8}$ A simple clinical measurement was carried out by P. Schober, ${ }^{10}$ who observed the degree of skin distraction between marks $10 \mathrm{~cm}$. apart, the lower being placed on the spinous process of the fifth lumbar vertebra. This method has recently been modified with considerable increase in accuracy ${ }^{11}$ and makes a useful simple test in clinical practice and epidemiological study. It has been shown that the ability to flex the back is very dependent on age in both sexes, though in all age groups the limitation of back movement is more in women than it is in men.

The explanation of these changes in various joints may be found in the alteration that collagen undergoes with advancing age. There is increase in fibril width, ${ }^{12}$ greater thermal contraction, ${ }^{13}$ decreased susceptibility to collagenase, ${ }^{14} 15$ and increased cross-linking within fibrils. ${ }^{13}$ Collagen in the human skin becomes stiffer with advancing age, ${ }^{16-18}$ and it may do so in the joint capsule also, thus causing the increased physical stiffness seen in older people. On the other hand it has also been suggested that the findings may be explained by a decrease in the viscosity of synovial fluid with increasing years ${ }^{19}$ together with a decrease in the resilience of cartilage owing to the death of superficial chondrocytes and the reduction of the content of chondroitin sulphate. ${ }^{20}$

These studies of stiffness are an important contribution to our understanding of the ageing process. In clinical practice they provide an objective measure of the progress of joint disease and the assessment of therapy. And they are helpful in epidemiological studies of conditions such as ankylosing spondylitis, in which limitation of back movement is a criterion of diagnosis. ${ }^{21} 22$

\section{Sulphur and Heart Disease}

Toxic effects resulting from exposure to carbon disulphide $\left(\mathrm{CS}_{2}\right)$ have been recognized since the middle of the nineteenth century. ${ }^{1}$ Neurological syndromes, psychoses, encephalopathy, and polyneuritis were first reported in workers in the rubber industry, in which carbon disulphide was used as a softening agent. Recognition of the hazard led to improved ventilation of premises in which the substance is used, and a threshold limit value of 20 p.p.m. of carbon disulphide in the atmosphere has been established. Since 1924, when poisoning by carbon disulphide became notifiable in the United Kingdom, very few cases have been reported here, 